\title{
Chemical Changes of Enamel Produced by Sodium Fluoride, Hydroxyapatite, Er:YAG Laser, and Combined Treatments
}

\author{
Alma Yadira Ceballos-Jiménez $\mathbb{D}^{\mathbb{D}}{ }^{1}$ Laura Emma Rodríguez-Vilchis $\mathbb{D}^{\mathrm{D}}{ }^{1}$ \\ Rosalía Contreras-Bulnes, ${ }^{1}$ Jesús Arenas Alatorre $\mathbb{D}^{\mathrm{D}},{ }^{2}$ Rogelio José Scougall-Vilchis $\mathbb{D}^{\mathrm{D}}{ }^{1}$ \\ Ulises Velazquez-Enriquez $\mathbb{D}^{\mathbb{1}}{ }^{1}$ and María de los Angeles Moyaho-Bernal ${ }^{1}$ \\ ${ }^{1}$ Universidad Autónoma del Estado de México, Facultad de Odontología, Centro de Investigación y Estudios Avanzados en \\ Odontología, Jesús Carranza esq. Paseo Tollocan, Col. Universidad, 50130 Toluca, MEX, Mexico \\ ${ }^{2}$ Universidad Nacional Autónoma de México, Departamento de Materia Condensada, Facultad de Ciencias UNAM, \\ Instituto de Física, Circuito Exterior s/n, Coyoacán, Cd. Universitaria, 04510 Ciudad de México, Mexico
}

Correspondence should be addressed to Laura Emma Rodríguez-Vilchis; rovilaster@gmail.com

Received 3 October 2017; Revised 27 January 2018; Accepted 15 February 2018; Published 2 April 2018

Academic Editor: Annette Wiegand

Copyright (c) 2018 Alma Yadira Ceballos-Jiménez et al. This is an open access article distributed under the Creative Commons Attribution License, which permits unrestricted use, distribution, and reproduction in any medium, provided the original work is properly cited.

Occlusal pits and fissures of permanent molars are considered to have higher risk of developing caries. Enamel demineralization can be prevented by applying remineralizing agents, and their absorption increases with prior irradiation. This work evaluates the chemical changes produced by treating occlusal surfaces with sodium fluoride (NaF), hydroxyapatite-NaF-xylitol (HA-NaF-X), Er:YAG laser irradiation (L), and combinations thereof. Fifty enamel samples were randomly assigned to five groups $(n=10)$ : $\mathrm{NaF}, \mathrm{HA}-\mathrm{NaF}-\mathrm{X}, \mathrm{L}, \mathrm{L}+\mathrm{NaF}$, and L + HA-NaF-X. The chemical composition of human enamel was evaluated before (BT) and after (AT) treatment using energy-dispersive X-ray spectroscopy (EDS) and expressed in atomic percentages (at\%). For combined treatment groups, the products were applied after laser irradiation. The statistical analyses included a paired $t$-test and ANOVA $(p \leq 0.05)$. After treatment, a significant increase in F at\% was observed in the NaF group $(2.71 \pm 1.41)$. The irradiated groups showed significant increases in $\mathrm{Ca}$ and $\mathrm{P}$ at $\%$ and the $\mathrm{Ca} / \mathrm{P}$ ratio. The highest values occurred for $\mathrm{L}+\mathrm{NaF}(30.44 \pm 4.28$ $\mathrm{Ca}$ at $\%, 11.97 \pm 1.45 \mathrm{P}$ at $\%$, and $2.55 \pm 0.22 \mathrm{Ca} / \mathrm{P}$ ratio). Er:YAG laser irradiation alone or in combined protocols increased the $\mathrm{Ca}$ and $\mathrm{P}$ content of dental enamel, in vitro.

\section{Introduction}

Despite the multiple advances in prevention, dental caries is still a public health problem [1]. There are dental surfaces where caries develop more frequently $[2,3]$, including the occlusal surfaces $[3,4]$. This is mainly due to the morphology of these surfaces, which are characterized by pits and fissures that favor the accumulation and proliferation of pathogenic caries organisms $[2,5,6]$.

Fluoride has been studied for decades and has shown to be effective in preventing tooth decay by inhibiting demineralization, enhancing remineralization, and reducing the metabolic activity of bacteria $[7,8]$. Fluorides are highly effective in reducing carious lesions that occur on the smooth surfaces of enamel. However, fluorides are not equally effective in protecting the occlusal pits and fissures, where the majority of carious lesions occur $[6,9]$. Therefore, it is necessary to study new strategies for the prevention of occlusal caries.

Alternative remineralizing agents are now available, such as hydroxyapatite (HA). Several studies report that such agents have anticariogenic properties that are explained by the contribution of minerals to the dental structure, which promote remineralization and inhibit demineralization. However, the use of such agents remains controversial [10-15].

Reports indicate that the structural composition in enamel after irradiation with an Er:YAG laser can favor acid resistance due to the loss of carbonate [16-21]. A combination of fluoride and laser treatments can also make the 


\begin{tabular}{|c|c|c|c|c|}
\hline \multicolumn{5}{|c|}{$\begin{array}{l}\text { Unerupted permanent third molars } \\
50 \text { enamel samples (occlusal surface) }\end{array}$} \\
\hline \multicolumn{5}{|c|}{$\begin{array}{l}\text { Analysis before treatment (BT) } \\
\text { by energy-dispersive X-ray spectroscopy (EDS) }\end{array}$} \\
\hline \multicolumn{5}{|c|}{ Occlusal surface treatment } \\
\hline $\begin{array}{c}\mathrm{NaF} \\
n=10\end{array}$ & $\begin{array}{c}\text { HA-NaF-X } \\
n=10\end{array}$ & $\begin{array}{c}\mathrm{L} \\
n=10\end{array}$ & $\begin{array}{c}\mathrm{L}+\mathrm{NaF} \\
n=10\end{array}$ & $\begin{array}{c}\mathrm{L}+\mathrm{HA}-\mathrm{NaF}-\mathrm{X} \\
n=10\end{array}$ \\
\hline \multicolumn{5}{|c|}{$\begin{array}{c}\text { Analysis after treatment (AT) } \\
\text { by energy-dispersive X-ray spectroscopy (EDS) }\end{array}$} \\
\hline
\end{tabular}

Figure 1: A diagram of the experimental design. For combined treatments, products were applied after laser irradiation.

enamel more resistant to acid than either treatment alone $[19,20,22-26]$. Unlike fluoride, there are few studies that combine the use of lasers and remineralizing agents. Therefore, the purpose of this study is to evaluate the chemical changes produced by sodium fluoride $(\mathrm{NaF})$, hydroxyapatite-NaF-xylitol (HA-NaF-X), Er:YAG laser irradiation (L), and combined treatments on the occlusal surface of permanent unerupted third molars.

\section{Materials and Methods}

2.1. Tooth Selection and Sample Preparation. The study protocol was approved by the Research Ethics Committee at the Dental Research and Advance Studies Center, School of Dentistry, at the Autonomous University of the State of Mexico (UAEM). All subjects enrolled in this research signed a consent form. Thirteen unerupted permanent third molars were extracted from 11 patients for therapeutic reasons and stored in $0.2 \%$ thymol solution at $4^{\circ} \mathrm{C}$ for a period of no longer than two months. The crown was separated from the root in each tooth using a diamond disc (BesQual, New York, NY) mounted on a low-speed motor (Brasseler, Savannah, GA) under distilled water irrigation to prevent dehydration. The crown was fixed to a glass slide with thermoplasticized epoxy resin (Allied, Rancho Dominguez, CA). Afterwards, a diamond wheel (South Bay Technology Inc.) was employed to obtain samples under constant irrigation $[18,25,27,28]$.

Buccolingual cuts were performed to remove the natural curvature of the mesial and distal surfaces of the crown to include pits and fissures on the occlusal surface. This portion was equally sectioned to obtain four samples with dimensions of $2 \mathrm{~mm} \times 5 \mathrm{~mm}$. A reference line was marked at $2 \mathrm{~mm}$ from the central occlusal fissure using a diamond disc (MDT Micro Diamond, Afula, Israel) mounted on a low-speed handpiece (MTI, New Jersey, USA) with water irrigation in order to delimit the area to be treated.

The samples were then cleaned for $5 \mathrm{~min}$ in separate containers filled with deionized water in an ultrasonic bath (Quantrex Q140, L\&R Ultrasonics, NJ, USA) and dried at room temperature [25]. Specimens were scanned with a laser-fluorescence caries-detection system, the DIAGNOdent pen (KaVo, Biderach, Germany), and 50 specimens showing

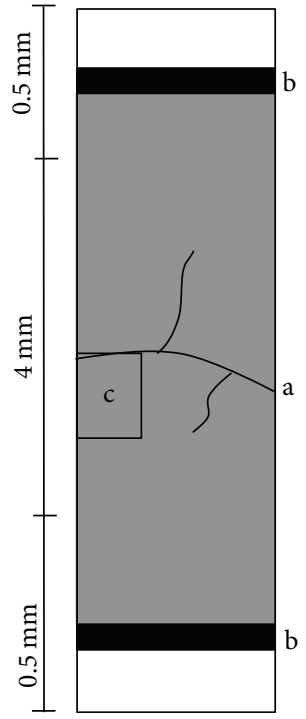

Figure 2: Occlusal view of the sample (enamel block). (a) Central occlusal fissure, (b) reference lines to delimit the area to be treated (gray color), (c) EDS area of analysis $(659 \mu m \times 500 \mu m)$.

values between 0 and 13 (healthy teeth) were selected for the study and assigned to each group having no samples coming from the same tooth for each group. A diagram of the experimental design is shown in Figure 1.

2.2. EDS. The occlusal surface at the top of the central fissure was analyzed on the right edge of the sample using a scanning electron microscope (JEOL, JSM-5600LV, Japan), as shown in Figure 2. An area of $659 \mu \mathrm{m} \times 500 \mu \mathrm{m}$ was visualized at 200x standardized magnification. The observations were carried out in a low-vacuum mode at a pressure of $9 \mathrm{~Pa}$ with an electron acceleration voltage of $15 \mathrm{kV}$, a working distance of $21 \mathrm{~mm}$, and backscatter detection. The atomic percentages (at\%) of carbon (C), oxygen (O), chlorine $(\mathrm{Cl})$, fluorine $(\mathrm{F})$, calcium $(\mathrm{Ca})$, and phosphorus $(\mathrm{P})$ were analyzed using an X-ray detector system (Thermo Scientific, 5225 Verona, Madison, USA) attached to the microscope. Energy-dispersive X-ray spectroscopy (EDS) was conducted before treatment (BT) and after treatment (AT). 
TABLE 1: Treatment by study groups.

\begin{tabular}{lc}
\hline Groups & Treatments \\
\hline NaF & Sodium fluoride \\
HA-NaF-X & Hydroxyapatite-NaF-xylitol \\
$\mathrm{L}$ & Er:YAG $100 \mathrm{~mJ}\left(12.7 \mathrm{~J} / \mathrm{cm}^{2}\right) 10 \mathrm{~Hz}$ \\
$\mathrm{~L}+\mathrm{NaF}$ & Er:YAG $100 \mathrm{~mJ}\left(12.7 \mathrm{~J} / \mathrm{cm}^{2}\right) 10 \mathrm{~Hz}+\mathrm{NaF}$ \\
$\mathrm{L}+\mathrm{HA}-\mathrm{NaF}-\mathrm{X}$ & Er:YAG $100 \mathrm{~mJ}\left(12.7 \mathrm{~J} / \mathrm{cm}^{2}\right) 10 \mathrm{~Hz}+$ \\
& hydroxyapatite-NaF-xylitol \\
\hline
\end{tabular}

2.3. Surface Treatments. Fifty occlusal enamel samples were randomly assigned to five groups of $10(n=10)$ (Table 1). The samples were treated individually, as described below.

2.3.1. Sodium Fluoride. The dental surface was dried, followed by the application of $1.1 \%(5457 \mathrm{ppm}$, calculated value) gel sodium fluoride at $\mathrm{pH}=6.5$ (Flor-Opal ${ }^{\circledR}$, Ultradent, Utah, USA) for 4 minutes. The samples were then rinsed with deionized water for $30 \mathrm{sec}$ and dried at room temperature.

2.3.2. Hydroxyapatite. The samples were treated with a water-based cream that contains $\mathrm{HA}, 1450 \mathrm{ppm}$ of $\mathrm{NaF}$, and xylitol (Remin Pro, VOCO, Cuxhaven, Germany) at $\mathrm{pH}=8.1$ (calculated value). The application time was $4 \mathrm{~min}$. The samples were then rinsed with deionized water for $30 \mathrm{sec}$ and dried at room temperature.

2.3.3. Er:YAG Laser Irradiation. An Er:YAG laser system (Lumenis OPUS DUO ${ }^{\mathrm{TM}}$ Er:YAG $+\mathrm{CO}_{2}$, Yokneam, Israel) was used to irradiate the samples of the groups subjected to the $\mathrm{L}, \mathrm{L}+\mathrm{NaF}$, and $\mathrm{L}+\mathrm{HA}-\mathrm{NaF}-\mathrm{X}$ treatments. The main experimental parameters of the laser during the study were as follows: a wavelength fixed at $2.94 \mu \mathrm{m}$, energy pulse of $100 \mathrm{~mJ}\left(12.7 \mathrm{~J} / \mathrm{cm}^{2}\right)$, frequency of $10 \mathrm{~Hz}$, pulse duration of $400 \mu \mathrm{sec}$, and an exit tip diameter of $1.0 \mathrm{~mm}$. The energy levels were calibrated using the calipers of the equipment, and the energy delivered was measured periodically with a power meter (Laser Mate-P, Coherent Co., Santa Clara, CA).

The irradiation was performed manually in one direction with the tip smoothly scanning perpendicularly to the samples' enamel surface, in the limited area as shown in gray color, in Figure 2. Simultaneously, distilled water was sprayed $(5.0 \mathrm{~mL} / \mathrm{min})$ to reduce heating. The distance between the tip and the sample was $1 \mathrm{~mm}$, which was ensured by using a sheet of stainless steel $(23 \mathrm{~mm} \times 5 \mathrm{~mm} \times 0.5 \mathrm{~mm})$ that was fixed to the top of the laser handpiece. At this tip-sample distance, the exit tip and the laser beam had the same diameter, which was confirmed by a laminated infrared sensor screen (Lumitek International Inc., Ijamsville, MD, USA) [18, 25, $27,28]$. Each sample was irradiated only once for $20 \mathrm{sec}$.

2.3.4. Combined Treatments. The samples in the $\mathrm{L}+\mathrm{NaF}$ and $\mathrm{L}+\mathrm{HA}-\mathrm{NaF}-\mathrm{X}$ groups were irradiated with an Er:YAG laser, and then a remineralizing agent $(\mathrm{NaF}$ or $\mathrm{HA}-\mathrm{NaF}-\mathrm{X})$ was applied immediately after. The parameters and techniques for the laser irradiation and remineralizing agent application were the same as those described previously.
2.4. Statistical Analysis. All the data were analyzed using SPSS software (SPSS IBM, New York, NY, USA), version 19. The tests included a Kolmogorov-Smirnov test to assess the data distribution and a paired $t$-test to compare the atomic percentages of the different elements before and after treatment. Subsequently, one-way analysis of variance (ANOVA) was used to compare among groups. When significant differences were found, Bonferroni or Tamhane's T2 post hoc tests were applied, depending on Levene's test of homogeneity of variance. The level of significance was $p \leq 0.05$ in all statistical analyses.

\section{Results}

3.1. EDS Evaluation. Tables 2 and 3 present the at $\%$ of $\mathrm{C}, \mathrm{O}$, $\mathrm{Cl}, \mathrm{F}, \mathrm{Ca}$, and $\mathrm{P}$ and the $\mathrm{Ca} / \mathrm{P}$ ratio obtained with $\mathrm{EDS}$ for all groups. Before treatment (natural enamel), no statistically significant differences were observed in the at $\%$ of elements analyzed among groups. The values were from $29.81 \pm 4.77$ to $36.63 \pm 8.64$ for $\mathrm{C}$ at\%, $50.52 \pm 8.12$ to $54.58 \pm 5.58$ for $\mathrm{O}$ at\%, $0.20 \pm 0.30$ to $0.46 \pm 0.64$ for $\mathrm{F}$ at\%, $7.15 \pm 1.63$ to $8.62 \pm 2.45$ for $\mathrm{Ca}$ at $\%, 5.36 \pm 0.92$ to $6.36 \pm 1.00$ for $\mathrm{P}$ at $\%$, and $1.32 \pm 0.23$ to $0.36 \pm 0.20$ for the $\mathrm{Ca} / \mathrm{P}$ ratio. After treatment, all elements evaluated by the group showed significant changes $(p \leq 0.05)$ except for the HA-NaF-X group, which did not present changes in at $\%$ for all elements analyzed. Only the $\mathrm{NaF}$ group displayed an increase in $\mathrm{F}$ at\% $(2.71 \pm 1.41, p \leq 0.05)$, while the irradiated groups showed significant decreases in $\mathrm{C}$ at\% (similar among them), as well as significant increases in $\mathrm{Ca}$ and $\mathrm{P}$ at $\%$ and the $\mathrm{Ca} / \mathrm{P}$ ratio. Nevertheless, the highest mineral values occurred for the $\mathrm{L}+\mathrm{NaF}$ group $(30.44 \pm 4.28 \mathrm{Ca}$ at $\%, 11.97 \pm 1.45 \mathrm{P}$ at $\%$, and $2.55 \pm 0.22 \mathrm{Ca} / \mathrm{P}$ ratio).

\section{Discussion}

Dental caries is still a major oral health problem in most industrialized countries, affecting $60-90 \%$ of schoolchildren and the vast majority of adults [1]. The first permanent molars are the teeth most susceptible to occlusal caries, which is mainly due to the complex occlusal morphology characterized by numerous pits and fissures $[3,6]$. In this research, samples were obtained from nonerupted third molars that had not been exposed to the oral environment and the associated variations in $\mathrm{pH}$, demineralization, and remineralization cycles. They were assigned consecutively to the groups in order to guarantee not having more than one sample from the same tooth for each group; this step was required to avoid bias among the changes produced by each treatment protocol.

There are limited reports regarding the element content in the same area of dental enamel during consecutive experimental phases (before and after treatment under several preventive protocols) $[18,25]$. Such analyses would allow for the objective measurement of the chemical changes that occur. The changes in $\mathrm{C}, \mathrm{O}, \mathrm{Cl}, \mathrm{F}, \mathrm{Ca}, \mathrm{P}$, and $\mathrm{Ca} / \mathrm{P}$ ratio were evaluated on the occlusal surface by EDS as atomic percentages (at\%), which allows us to determine directly the present number of atoms per element, unlike the weight percentage 


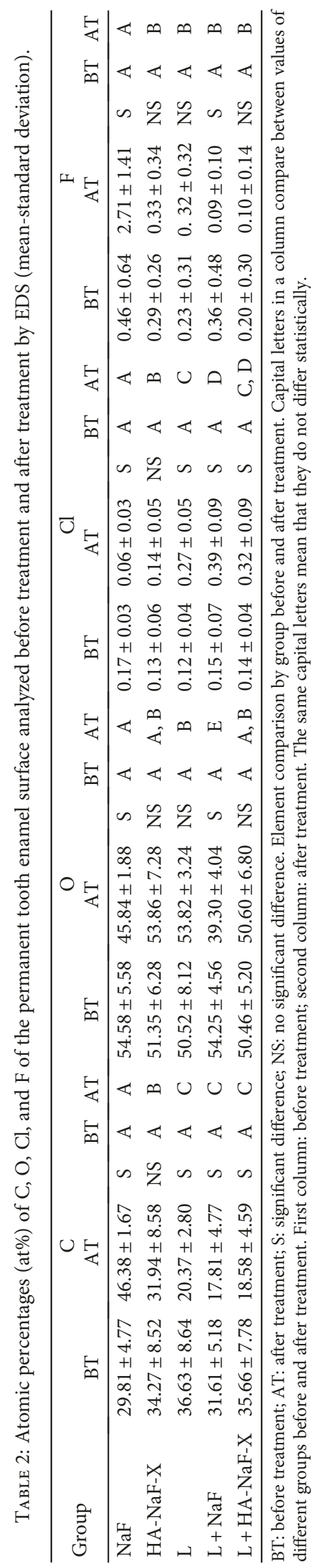


TABle 3: Atomic percentages (at\%) of $\mathrm{Ca}$ and $\mathrm{P}$ and $\mathrm{Ca} / \mathrm{P}$ ratio of the permanent tooth enamel surface analyzed before treatment and after treatment by EDS (mean-standard deviation).

\begin{tabular}{|c|c|c|c|c|c|c|c|c|c|c|c|c|c|c|c|}
\hline \multirow{2}{*}{ Group } & \multicolumn{4}{|c|}{$\mathrm{Ca}$} & \multicolumn{6}{|c|}{$\mathrm{P}$} & \multicolumn{5}{|c|}{$\mathrm{Ca} / \mathrm{P}$} \\
\hline & BT & $\mathrm{AT}$ & & BT & AT & BT & $\mathrm{AT}$ & & BT & AT & BT & $\mathrm{AT}$ & & BT & AT \\
\hline $\mathrm{NaF}$ & $8.62 \pm 2.45$ & $2.97 \pm 1.57$ & $S$ & $\mathrm{~A}$ & $\mathrm{~A}$ & $6.36 \pm 1.00$ & $2.04 \pm 1.09$ & $S$ & $\mathrm{~A}$ & A & $1.34 \pm 0.21$ & $1.52 \pm 0.34$ & $S$ & A & $A, B$ \\
\hline HA-NaF-X & $8.06 \pm 3.17$ & $7.86 \pm 2.51$ & NS & A & B & $5.90 \pm 1.84$ & $5.87 \pm 1.45$ & NS & A & B & $1.34 \pm 0.15$ & $1.32 \pm 0.16$ & NS & A & A \\
\hline $\mathrm{L}$ & $7.15 \pm 1.63$ & $15.79 \pm 2.38$ & $S$ & A & $\mathrm{C}$ & $5.36 \pm 0.92$ & $9.44 \pm 0.79$ & $S$ & A & $\mathrm{C}$ & $1.33 \pm 0.13$ & $1.67 \pm 0.14$ & S & A & B \\
\hline $\mathrm{L}+\mathrm{NaF}$ & $7.83 \pm 3.11$ & $30.44 \pm 4.28$ & S & A & $\mathrm{D}$ & $5.80 \pm 1.59$ & $11.97 \pm 1.45$ & S & A & $\mathrm{D}$ & $1.32 \pm 0.23$ & $2.55 \pm 0.22$ & S & $\mathrm{A}$ & $\mathrm{C}$ \\
\hline $\mathrm{L}+\mathrm{HA}-\mathrm{NaF}-\mathrm{X}$ & $7.86 \quad 2.94$ & $19.95 \pm 6.64$ & S & A & $\mathrm{C}$ & $5.69 \pm 1.69$ & $10.45 \pm 1.30$ & S & A & C, D & $1.36 \pm 0.20$ & $1.88 \pm 0.45$ & S & A & B \\
\hline
\end{tabular}

BT: before treatment; AT: after treatment; S: significant difference; NS: no significant difference. Element comparison by group before and after treatment. Capital letters in a column compare between values of different groups before and after treatment. First column: before treatment; second column: after treatment. The same capital letters mean that they do not differ statistically.

(wt\%), which varies per element. In this way, changes in the chemical composition can be observed easily.

Additionally, the irradiation parameters were chosen according to the results of a pilot study that was designed after a literature review $[16,18,20,29,30]$. The enamel acid resistance achieved varies according to the type of laser used for this purpose, which have specific parameters. For the Er:YAG laser, Liu et al. suggested that the optimal laser energy for preventing enamel demineralization is $12.7 \mathrm{~J} / \mathrm{cm}^{2}$ [29]. This energy density with water irrigation (as employed in this study) is also considered as safe for pulp protection $[20,31]$. For this reason, when combined treatments were used, they were applied after irrigated laser irradiation.

The results showed specific chemical changes that depended on the preventive protocol applied. The NaF group showed significant changes in all elements evaluated, with most showing a decrease $(\mathrm{O}, \mathrm{Cl}, \mathrm{Ca}$, and $\mathrm{P})$. This could have occurred at the expense of increases in $\mathrm{C}$ and $\mathrm{F}$ at\%. These results are comparable with those reported by ZamudioOrtega et al. [25], who applied acidulated phosphate fluoride (APF), although their study was performed on the smooth surfaces of temporary teeth.

It has been reported that neutral $\mathrm{NaF}$ solutions with fluoride concentrations of $100 \mathrm{ppm}$ or less primarily resulted in the formation of fluorapatite, whereas higher fluoride concentrations resulted in the formation of calcium fluoride on the enamel surface [31]. The applied $\mathrm{NaF}$ product has a $\mathrm{pH}$ of 6.5 according to the manufacturer, which is close to neutral $\mathrm{pH}$. Coupled with the high ppm (more than 5000 ), this could explain why increases in F at\% occurred in only this study group. Additional studies are recommended to determine what fluoride-based compound forms under these conditions.

No chemical changes were found for the HA-NaF-X group. However, Gjorgievska et al. [14] suggest that HA particles in toothpaste react with the enamel surface, and the increased $\mathrm{Ca}$ and $\mathrm{P}$ concentrations result in the repair of demineralized surfaces. Furthermore, remnants present as deposits on the enamel surface can be used as $\mathrm{Ca}$ and $\mathrm{P}$ sources if future acid attacks occur. However, it seems that the application of HA-NaF-X alone is not enough to achieve this goal. Gravila et al. [15] reported higher $\mathrm{Ca}$ and $p$ values (wt\%) when HA was applied with fluoride twice a day for 14 days compared with fluoride products. The lack of increase in $\mathrm{F}$ at\% could be due to the lower $\mathrm{F}$ concentration
(1450 ppm) and the $\mathrm{pH}$ of 8.1 of the product employed in this group, in contrast to the $\mathrm{NaF}$ group. This highlights the fact that groups treated with Er:YAG laser irradiation exhibited similar patterns of chemical changes except for O. In either combined or single treatments, this element shows a parallel pattern according to remineralizing agent employed.

Only the irradiated groups showed a decrease of $\mathrm{C}$ at $\%$. This could be explained by the decreased enamel solubility theory, which involves changes in the ultrastructure, such as reductions in the water and carbonate contents, an increase in the hydroxyl ion content, pyrophosphate formation, and protein decomposition $[20,32]$. In relation to the lack of changes in the $\mathrm{F}$ at $\%$ content in irradiated groups, it seems that the laser irradiation parameters employed do not favor $\mathrm{NaF}$ uptake in the enamel structure when a single fluoride application is performed. However, Liu et al. [24] reported that low-energy Er:YAG laser irradiation coupled with $2.0 \% \mathrm{NaF}$ treatment may inhibit enamel demineralization through increased fluoride deposition on the enamel surface, among other associated mechanisms.

Furthermore, the increases in the $\mathrm{Ca}$ at $\%, \mathrm{P}$ at $\%$, and $\mathrm{Ca} / \mathrm{P}$ ratio in all irradiated groups suggest that the dental chemical structure of enamel could be favored. This is in accordance with Díaz-Monroy et al. [18], who reported that chemical changes after acid dissolution showed stable or increased atomic $\mathrm{Ca} / \mathrm{P}$ ratios among Er:YAG laserirradiated groups. These groups showed a reduction of $\mathrm{Ca}$ released into the acid solution associated with an increased acid resistance of the enamel. The combined treatment of laser and $\mathrm{NaF}$ produced the most evident increase in $\mathrm{Ca} / \mathrm{P}$ ratio, which was probably at the expense of a great increase in $\mathrm{Ca}$ at $\%$. This is similar to the results obtained when a combination of Er:YAG laser treatment $\left(39.8 \mathrm{~J} / \mathrm{cm}^{2}\right)$ and acidulated phosphate fluoride was applied to the primary enamel [25]. In this study group, the $\mathrm{Ca} / \mathrm{P}$ ratio was higher than the stoichiometric ratio for pure hydroxyapatite (1.67). The $\mathrm{Ca} / \mathrm{P}$ ratio is considered as a reliable indicator of tooth mineralization, independent of changes in other elements of the dental structure [25].

There are also other promising strategies for the prevention of caries and erosion. Several studies have shown that $\mathrm{CO}_{2}$ laser is very effective for the prevention of tooth decay and dental erosion under previously established parameters in comparison to Er:YAG laser, among other approaches [33-35]. However, based on the favorable chemical changes 
observed that could improve the enamel structure, it is suggested that additional studies be carried out to evaluate the acid resistance of enamel for the establishment of alternative preventive protocols and protect areas that are susceptible to caries, such as occlusal surfaces.

\section{Conclusions}

Each preventive protocol produced particular chemical changes. The application of $1.1 \% \mathrm{NaF}$ produced a significant increase in $\mathrm{F}$ at $\%$ in the dental structure, and a stable $\mathrm{Ca} / \mathrm{P}$ ratio was observed. The application of HA-NaF-X does not produce any change when used as a single treatment. However, in combination with Er:YAG laser, it shows a similar pattern to the irradiated groups. The Er:YAG laser irradiation alone or in combined treatments could favor the mineral content of the enamel structure by increasing the $\mathrm{Ca}$ at $\%$, $\mathrm{P}$ at\%, and $\mathrm{Ca} / \mathrm{P}$ ratio.

\section{Conflicts of Interest}

The authors declare that there is no conflict of interest regarding the publication of this paper.

\section{Acknowledgments}

The authors thank David Villanueva Jurado, a maxillofacial surgeon from the School of Dentistry, Universidad Autónoma del Estado de México, for the support in obtaining the samples. This project was financed by the Universidad Nacional Autónoma de México and Universidad Autónoma del Estado de México.

\section{References}

[1] P. E. Petersen, D. Bourgeois, H. Ogawa, S. Estupinan-Day, and C. Ndiaye, "The global burden of oral diseases and risks to oral health," Bulletin of the World Health Organization, vol. 83, no. 9, pp. 661-669, 2005.

[2] A. M. Correa-Afonso, J. C. Ciconne-Nogueira, J. D. Pécora, and R. G. Palma-Dibb, "In vitro assessment of laser efficiency for caries prevention in pits and fissures," Microscopy Research and Technique, vol. 75, no. 2, pp. 245-252, 2012.

[3] M. Demirci, S. Tuncer, and A. A. Yuceokur, "Prevalence of caries on individual tooth surfaces and its distribution by age and gender in university clinic patients," European Journal of Dentistry, vol. 4, no. 3, pp. 270-279, 2010.

[4] M. Barman, A. Tirth, V. Tandon, S. Chandra, and T. S. Ain, "Prevalence of dental caries in first permanent molars among 12 years school going children in Purba Medinipur City, West Bengal," International Research Journal of Clinical Medicine, vol. 1, pp. 12-15, 2016.

[5] A. M. Correa-Afonso, J. D. Pécora, and R. G. Palma-Dibb, "Influence of laser irradiation on pits and fissures: an in situ study," Photomedicine and Laser Surgery, vol. 31, no. 2, pp. 82-89, 2013.

[6] J. T. Wrigth, M. P. Tampi, L. Graham et al., "Sealants for preventing and arresting pit and fissure oclusal caries in primary and permanent molars," Pediatric Dentistry, vol. 38, no. 4, pp. 282-294, 2016.
[7] J. Hicks, F. García-Godoy, and C. Flaitz, "Biological factors in dental caries: role of remineralization and fluoride in the dynamic process of demineralization and remineralization (part 3)," Journal of Clinical Pediatric Dentistry, vol. 28, no. 3, pp. 203-214, 2004.

[8] S. Jones, B. A. Burt, P. E. Petersen, and M. A. Lennon, "The effective use of fluorides in public health," Bulletin of the World Health Organization, vol. 83, no. 9, pp. 670-676, 2005.

[9] J. Beauchamp, P. W. Caufield, J. J. Crall et al., "Evidence based clinical recommendations for the use of pit and fissure sealants a report of the American Dental Association Council on Scientific Affairs," Journal American Dental Association, vol. 139, no. 3, pp. 257-268, 2008.

[10] A. Azarpazhooh and H. Limeback, "Clinical efficacy of casein derivatives," The Journal of the American Dental Association, vol. 139, no. 7, pp. 915-924, 2008.

[11] S. Raphael and A. Blinkhorn, "Is there a place for Tooth Mousse in the prevention and treatment of early dental caries? A systematic review," BMC Oral Health, vol. 15, no. 1, p. 113, 2015.

[12] F. Ulkur, E. Sungurtekin Ekçi, D. Nalbantgil, and N. Sandalli, "In vitro effects of two topical varnish materials and Er:YAG laser irradiation on enamel demineralization around orthodontic brackets," The Scientific World Journal, vol. 2014, Article ID 490503, 7 pages, 2014.

[13] S. Huang, S. Gao, L. Cheng, and H. Yu, "Remineralization potential of nano-hydroxyapatite on initial enamel lesions: an in vitro study," Caries Research, vol. 45, no. 5, pp. 460 468, 2011.

[14] E. S. Gjorgievska, J. W. Nicholson, I. J. Slipper, and M. M. Stevanovic, "Remineralization of demineralized enamel by toothpastes: a scanning electron microscopy, energy dispersive $\mathrm{X}$-ray analysis, and three-dimensional stereo-micrographic study," Microscopy and Microanalysis, vol. 19, no. 03, pp. 587-595, 2013.

[15] L. Gravila, A. Maxim, A. Balam et al., "Comparative study regarding the effect of different remineralizing products on primary and permanent teeth enamel caries lesions," Revista de Chimie, vol. 8, pp. 1159-1161, 2015.

[16] R. C. M. Cecchini, D. M. Zezell, E. de Oliveira, P. M. de Freitas, and C. d. P. Eduardo, "Effect of Er:YAG laser on enamel acid resistance: morphological and atomic spectrometry analysis," Lasers in Surgery and Medicine, vol. 37, no. 5, pp. 366-372, 2005.

[17] Y. Liu, C. Y. S. Hsu, C. M. J. Teo, and S. H. Teoh, "Subablative Er:YAG laser effect on enamel demineralization," Caries Research, vol. 47, no. 1, pp. 63-68, 2013.

[18] J. M. Díaz-Monroy, R. Contreras-Bulnes, O. F. Olea-Mejía et al., "Chemical changes associated with increased acid resistance of Er:YAG laser irradiated enamel," The Scientific World Journal, vol. 2014, Article ID 501357, 6 pages, 2014.

[19] P. A. Ana, L. Bachmann, and D. M. Zezell, "Lasers effects on enamel for caries prevention," Laser Physics, vol. 16, no. 5, pp. 865-875, 2006.

[20] F. M. Bevilácqua, D. M. Zezell, R. Magnani, P. A. da Ana, and C. de Paula Eduardo, "Fluoride uptake and acid resistance of enamel irradiated with Er:YAG laser," Lasers in Medical Science, vol. 23, no. 2, pp. 141-147, 2008.

[21] M. Karandish, "The efficiency of laser application on the enamel surface: a systematic review," Journal of Lasers in Medical Sciences, vol. 5, no. 3, pp. 108-114, 2014. 
[22] J. Hicks, C. Flaitz, R. Ellis, G. Westerman, and L. Powell, "Primary tooth enamel surface topography with in vitro argon laser irradiation alone and combined fluoride and argon laser treatment: scanning electron microscopic study," Pediatric Dentistry, vol. 25, no. 5, pp. 491-496, 2003.

[23] M. M. Iqbal Hossain, M. Hossain, Y. Kimura, J.-I. Kinoshita, Y. Yamada, and K. Matsumoto, "Acquired acid resistance of enamel and dentin by $\mathrm{CO}_{2}$ laser irradiation with sodium fluoride solution," Journal of Clinical Laser Medicine \& Surgery, vol. 20, no. 2, pp. 77-82, 2002.

[24] Y. Liu, C. Y. S. Hsu, C. M. J. Teo, and S. H. Teoh, "Potential mechanism for the laser-fluoride effect on enamel demineralization," Journal of Dental Research, vol. 92, no. 1, pp. 71-75, 2012.

[25] C. M. Zamudio-Ortega, R. Contreras-Bulnes, R. J. ScougallVilchis et al., "Morphological and chemical changes of deciduous enamel produced by Er:YAG laser, fluoride and combined treatment," Photomedicine and Laser Surgery, vol. 32, no. 5, pp. 252-259, 2014.

[26] F. A. Curylofo-Zotti, G. Solano Tanta, A. L. Zugliani, and S. A. Milori Corona, "The combined use of sodium fluoride and Er:YAG laser to control the progression of enamel caries," European Journal of Pharmaceutical and Medical Research, vol. 3, no. 9, pp. 1-5, 2016.

[27] L. E. Rodríguez-Vilchis, R. Contreras-Bulnes, I. SánchezFlores, and E. C. Samano, "Acid resistance and structural changes of human dental enamel treated with Er:YAG laser," Photomedicine and Laser Surgery, vol. 28, no. 2, pp. 207-211, 2010.

[28] L. E. Rodríguez-Vilchis, R. Contreras-Bulnes, O. F. Olea-Mejìa, I. Sánchez-Flores, and C. Centeno-Pedraza, "Morphological and structural changes on human dental enamel after Er:YAG laser irradiation: AFM, SEM and EDS evaluation," Photomedicine and Laser Surgery, vol. 29, no. 7, pp. 493-500, 2011.

[29] J.-f. Liu, Y. Liu, and H. C.-Y. Stephen, "Optimal Er:YAG laser energy for preventing enamel demineralization," Journal of Dentistry, vol. 34, no. 1, pp. 62-66, 2006.

[30] D. Fried, S. R. Visuri, J. D. Featherstone et al., "Infrared radiometry of dental enamel during Er:YAG and Er:YSGG laser irradiation," Journal of Biomedical Optics, vol. 1, no. 4, pp. 455-465, 1996.

[31] N. O. Harris, F. García-Godoy, and C. N. Nathe, Primary Preventive Dentistry, Pearson, United States of America, 8th edition, 2014.

[32] B. O. Fowler and S. Kuroda, "Changes in heated and in laser-irradiated human tooth enamel and their probable effects on solubility," Calcified Tissue International, vol. 38, no. 4, pp. 197-208, 1986.

[33] M. Esteves-Oliveira, D. M. Zezell, J. Meister et al., " $\mathrm{CO}_{2}$ laser $(10.6 \mu \mathrm{m})$ parameters for caries prevention in dental enamel," Caries Research, vol. 43, no. 4, pp. 261-268, 2009.

[34] M. Esteves-Oliveira, N. Witulski, R.-D. Hilgers, C. Apel, H. Meyer-Lueckel, and C. de Paula Eduardo, "Combined tin-containing fluoride solution and $\mathrm{CO}_{2}$ laser treatment reduces enamel erosion in vitro," Caries Research, vol. 49, no. 6, pp. 565-574, 2015.

[35] M. Esteves-Oliveira, S. Wollgarten, S. Liebegall et al., "A new laser-processing strategy for improving enamel erosion resistance," Journal of Dental Research, vol. 96, no. 10, pp. 11681175, 2017. 

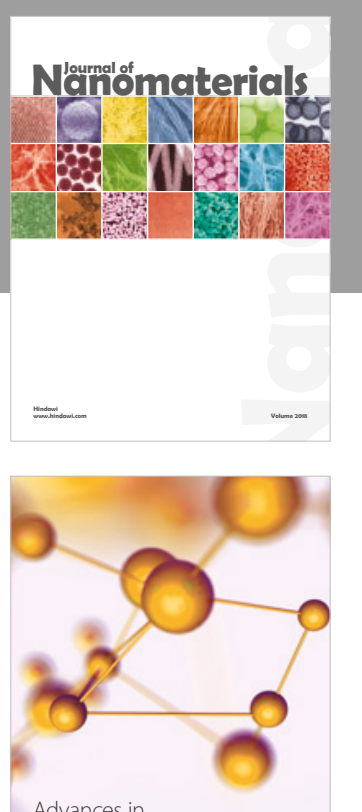

Physical Chemistry
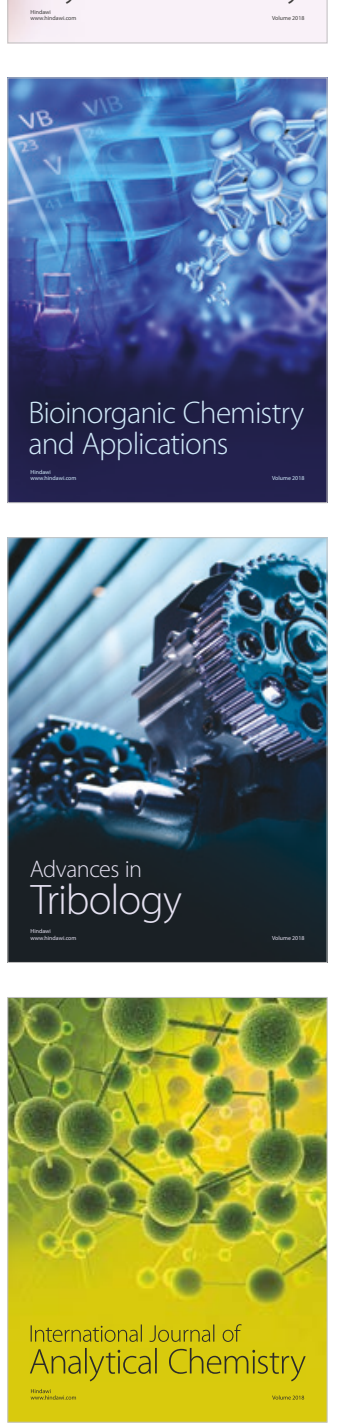

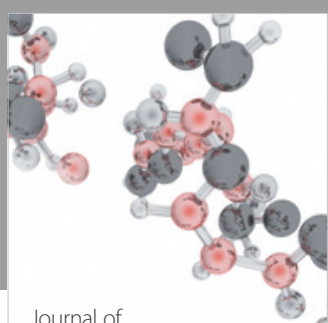

Analytical Methods

in Chemistry

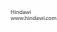

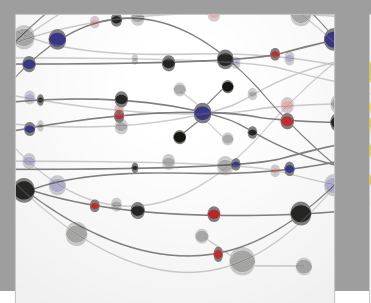

The Scientific World Journal

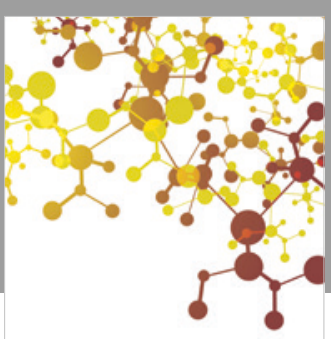

Journal of

Applied Chemistry
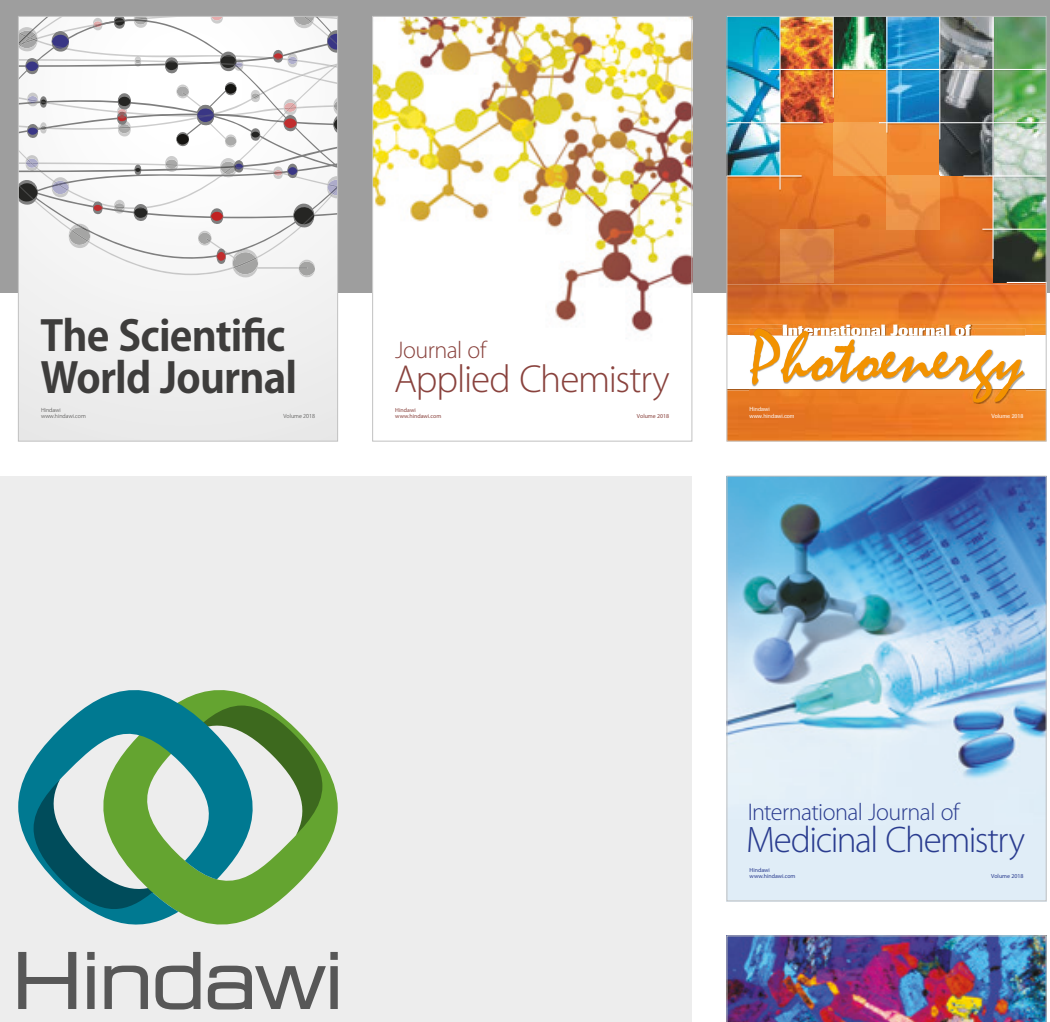

Submit your manuscripts at

www.hindawi.com
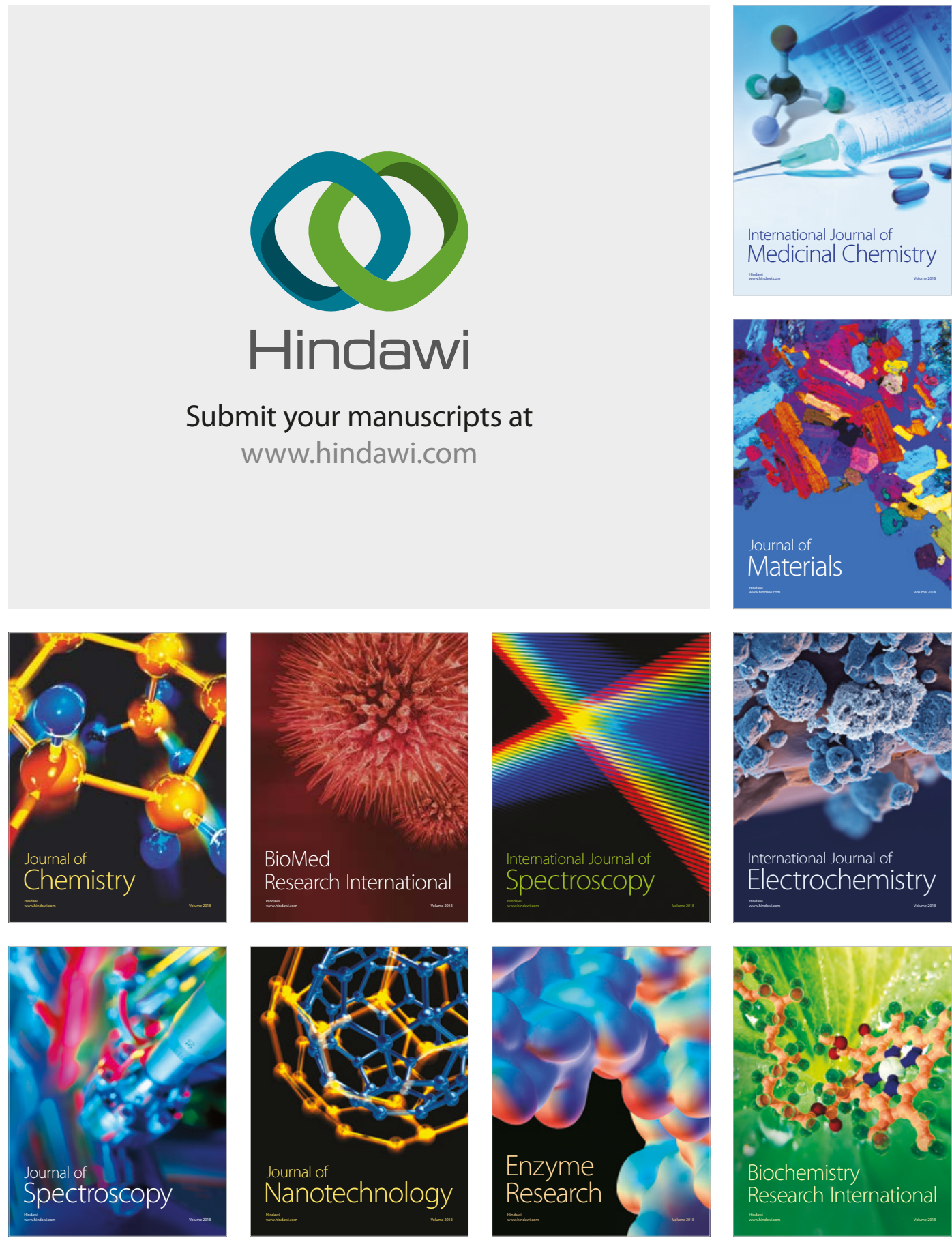
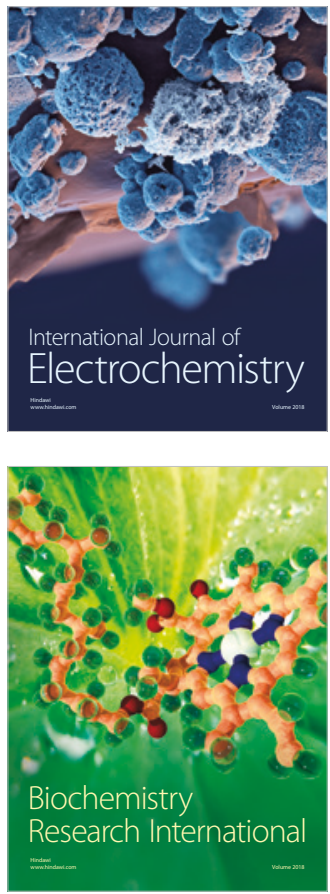